\title{
Bilateral Pulmonary Arteries Reconstruction for Correction of Tetralogy of Fallot with Unilateral Absence of the Pulmonary Artery
}

\author{
Hujun Cui ${ }^{1}$, Yongchao Yang ${ }^{2}$, Hailong Qiu², Jianzheng Cen ${ }^{2}$, Shusheng Wen ${ }^{2}$, Jian \\ Zhuang $^{2}$, and Jimei Chen ${ }^{2}$ \\ ${ }^{1}$ Department of Cardiac surgery Guangdong Provincial People’s Hospital Guangdong \\ Academy of Medical Sciences \\ ${ }^{2}$ Guangdong Provincial People's Hospital
}

November 12, 2021

\begin{abstract}
Background: Tetralogy of Fallot (TOF) is the most common combined the deformity of unilateral absence of the pulmonary artery (UAPA). The treatment strategy of TOF combined with UAPA is still very controversial. In this study, we analyzed the effect of the bilateral pulmonary reconstruction for patients with TOF combined with UAPA. Methods: A single-institution, retrospective review of all 1713 patients with TOF between January 2009 to November 2021. Eight patients were diagnosed with TOF combined with UAPA, and 7 patients underwent the surgery. Three patients underwent one-stage TOF correction with bilateral pulmonary artery reconstruction. Three patients underwent bilateral pulmonary artery reconstruction, followed by two-stage TOF correction after several months. One patient underwent 2 procedures of left pulmonary artery reconstruction, and the VSD remained open. Results: All 7 patients survived during the postoperative follow-up and showed good cardiac function and normal oxygen saturation $>97 \%$. During the follow-up with echocardiograms, it was found that the left pulmonary arteries that were reconstructed with Goretex vessel or direct anastomosis had thrombosis or stenosis. The left pulmonary artery reconstructed with the modified autologous tissue extension technique was unobstructed. Conclusions: In patients with TOF and UAPA, if there is a pulmonary confluence in the affected hilum, it is feasible to implement bilateral pulmonary artery reconstruction for one-stage TOF correction. The use of pulmonary artery extension technique and autologous tissue to bilateral pulmonary reconstruct could reduce the incidence of anastomotic stenosis.
\end{abstract}

Bilateral Pulmonary Arteries Reconstruction for Correction of Tetralogy of Fallot with Unilateral Absence of the Pulmonary Artery

Hujun Cui,MD ${ }^{1}$; Yongchao Yang,MD ${ }^{1}$; Hailong Qiu,MD ${ }^{1}$; Jianzheng Cen,MD ${ }^{1}$; Shusheng Wen,MD ${ }^{1}$; Jian Zhuang, $\mathrm{MD}^{1}$; Jimei Chen, $\mathrm{MD}^{1}$

Department of Cardiac surgery, Guangdong Provincial People's Hospital, Guangdong Academy of Medical Sciences

Total word count : 3212

Funding: The author(s) received no financial support for the research, authorship, and/or publication of this article.

Disclosures: All authors have nothing to disclose with regard to commercial support

Corresponding authors: 
Hujun Cui, MD

Department of Cardiac Surgery

Guangdong Provincial People's Hospital, Guangdong Academy of Medical Sciences

No. 106, Zhongshan 2 Road, Guangzhou, China

e-mail:drcuihj@163.com

Bilateral Pulmonary Arteries Reconstruction for Correction of Tetralogy of Fallot with Unilateral Absence of the Pulmonary Artery

Hujun Cui, Yongchao Yang, Hailong Qiu, Jianzheng Cen, Shusheng Wen, Jian Zhuang

Department of Cardiac surgery, Guangdong Provincial People's Hospital, Guangdong Academy of Medical

Sciences

Abstract

Background: Tetralogy of Fallot (TOF) is the most common combined the deformity of unilateral absence of the pulmonary artery (UAPA). The treatment strategy of TOF combined with UAPA is still very controversial. In this study, we analyzed the effect of the bilateral pulmonary reconstruction for patients with TOF combined with UAPA.

Methods: A single-institution, retrospective review of all 1713 patients with TOF between January 2009 to November 2021. Eight patients were diagnosed with TOF combined with UAPA, and 7 patients underwent the surgery. Three patients underwent one-stage TOF correction with bilateral pulmonary artery reconstruction. Three patients underwent bilateral pulmonary artery reconstruction, followed by two-stage TOF correction after several months. One patient underwent 2 procedures of left pulmonary artery reconstruction, and the VSD remained open.

Results: All 7 patients survived during the postoperative follow-up and showed good cardiac function and normal oxygen saturation $>97 \%$. During the follow-up with echocardiograms, it was found that the left pulmonary arteries that were reconstructed with Goretex vessel or direct anastomosis had thrombosis or stenosis. The left pulmonary artery reconstructed with the modified autologous tissue extension technique was unobstructed.

Conclusions: In patients with TOF and UAPA, if there is a pulmonary confluence in the affected hilum, it is feasible to implement bilateral pulmonary artery reconstruction for one-stage TOF correction. The use of pulmonary artery extension technique and autologous tissue to bilateral pulmonary reconstruct could reduce the incidence of anastomotic stenosis.

\section{Keywords}

Pulmonary artery, Pulmonary circulation, Heart defects, congenital, Tetralogy of Fallot

\section{INTRODUCTION}

Unilateral absence of pulmonary artery (UAPA) is a group congenital heart defect of complete absence of the intra-pericardial segment of one main pulmonary artery branch [1]. UAPA can exist alone or combined with other intracardiac malformations. About $0.95 \%$ to $3.23 \%$ of Tetralogy of Fallot (TOF) is combined with UAPA, and approximately 100 cases have been reported in the literature before 2014 [1,2]. The management of TOF combined with UAPA is still very controversial. According to the indications of classic TOF correction, it is difficult to reach the criteria of one-stage correction with McGoon index $>1.2$. The literature reported that the vast majority of such patients are treated with palliative surgery or unilateral pulmonary artery reconstruction (single-lung repair) instead of bilateral pulmonary artery reconstruction (two-lung repair) $[1,3,4]$. 
In this study, we reviewed the bilateral pulmonary reconstruction in patients with TOF combined with UAPA at our institute and discussed the therapeutic effect of this strategy.

\section{PATIENTS AND METHODS}

\section{Study Population and Definitions}

This was a retrospective review of patients from January 2009 to November 2021 at Guangdong Provincial People's Hospital. This study was approved by the Guangdong Provincial People's Hospital Institutional Review Board. The requirement for individual patient consent was waived. Data was obtained from a review of hospital charts and medical records.

During this period, a total of 1713 patients were diagnosed with TOF at our institute. 8 cases of TOF with UAPA were enrolled, excluding patients with intra-pericardial unilateral pulmonary artery occlusion or unilateral pulmonary artery originating from the aorta. The absent pulmonary artery in all patients was on the left side. Baseline demographics and patient characteristics are presented in Table 1, and the CT 3D print models of the pulmonary artery are shown in Figure 1.

\section{Surgical Procedure}

Except for one patient (Case 8) who refused surgical treatment due to combined with left diaphragmatic eventration and severe restrictive ventilatory disorder, 7 patients underwent surgery.

All 7 patients underwent bilateral pulmonary artery reconstruction. Different surgeons have chosen different surgical strategies and techniques. Three patients underwent one-stage TOF correction with bilateral pulmonary artery reconstruction (Case 3, Case 6, and Case 7). Three patients underwent bilateral pulmonary artery reconstruction as the first intervention, followed by two-stage TOF correction after several months (Case 1, Case 2, and Case 4). One patient underwent 2 procedures of left pulmonary artery reconstruction, and the VSD remained open currently (Case 5). See Table 2 for the detail of the operations.

The Goretex vessel was used to reconstruct the left pulmonary artery in 3 patients (Case 1, Case 4 and Case 5). In 2 patients, the posterior wall of the left pulmonary artery was directly anastomosed with the main pulmonary artery, and the anterior wall was widened by a pericardial patch (Case 2 and Case 3). In the other 2 patients, a modified technique was applied: a U-shaped vascular wall was cut from the left side of the main pulmonary artery, turned over and anastomosed with the posterior wall of the left pulmonary artery, and the anterior wall was widened with an autologous fresh pericardial patch (Case 6 and Case 7). The sketch of the modified procedure is shown in Figure 2.

TOF repair is in accordance with classic technical specifications: pericardium patch repairs ventricular septal defect; Transannular patch or non-transannular patch (the pulmonary artery and right ventricular outflow tract were widened respectively) according to the development of pulmonary valve annulus. Patients with coronary artery crossing the right ventricular outflow tract used a tube sewed with autologous pericardium to connect the main pulmonary and right ventricular outlet tract.

\section{Follow-up}

Serial echocardiograms and ECG were recorded every $3 \sim 6$ months post-operatively at our hospital. Hemodynamic and flow data from cardiac catheterization or cardiac CT were recorded, when available.

\section{Statistical Analysis}

Data are presented as mean \pm standard deviation and range or median and range. The unpaired Student's $t$ test was used to compare continuous variables before and after the procedure. Statistical significance was set at $\mathrm{p}<0.05$. Statistical analyses were performed using statistical software (SPSS v17.0; SPSS Inc., Chicago, IL, USA).

\section{RESULTS}


Seven patients underwent bilateral pulmonary arteries reconstruction, with a median age of 26 months (3 months to 44 months). At the time of admission, the patients had an average oxygen saturation of $72.5 \%$ (68\%-82\%) at rest.

The standard McGoon Index and Nakata Index were $0.86 \pm 0.11(0.7-1)$ and $117.1 \pm 37.5 \mathrm{~mm}^{2} / \mathrm{m}^{2}(68.9-144.5$ $\mathrm{mm}^{2} / \mathrm{m}^{2}$ ). If the diameter of the left pulmonary artery at the hilum was included in the calculation formula, the modified McGoon Index and Nakata Index were $1.34 \pm 0.15(1.1-1.6)$ and $149.9 \pm 30.9 \mathrm{~mm}^{2} / \mathrm{m}^{2}(99.6-204.4$ $\mathrm{mm}^{2} / \mathrm{m}^{2}$ ) respectively. So far, 6 patients have finally achieved TOF repair with bilateral pulmonary artery reconstruction (two-lung repair), and 3 of them underwent one-stage correction.

All patients survived during the postoperative follow-up and showed good cardiac function and normal oxygen saturation $>97 \%$, with a mean follow-up time of $2.4 \pm 1.4$ years ( $5 \mathrm{~m}-4.5$ years). During the followup with echocardiograms, it was found that all the left pulmonary arteries that were reconstructed with Goretex vessel had thrombosis, which led to varying degrees of stenosis or even complete occlusion, even though warfarin has been used for anticoagulation therapy. Severe stenosis or even occlusion occurred early after direct anastomosis to reconstruct the left pulmonary artery. The left pulmonary artery reconstructed with the modified anastomosis technique was unobstructed, and the CT image is shown in Figure 3.

\section{DISSCUSION}

Unilateral absence of pulmonary artery (UAPA) is a rare malformation that can present as an isolated lesion or may be associated with other congenital heart defects. Although TOF is the most common combined deformity of UAPA, the literature available is limited to small case series or case reports. Due to the scarcity of cases and the anatomical variation, the diagnostic criteria, embryological origin, and clinical classification of UAPA are still very controversial $[2,5]$. Although there is a hypothesis that UAPA is caused by the failure of the sixth aortic arch to connect with the pulmonary trunk during embryologic development [6], it still cannot explain that TOF combined with UAPA is more common in the left pulmonary artery. Barram and his colleagues [1] classified TOF combined with UAPA into four types. However, according to Congenital Heart Surgery Nomenclature and Database Project [7], those cases of the unilateral pulmonary artery originating from the ascending aorta or supplied by the arterial duct should be included in the category of aortopulmonary window. Therefore, these patients were not included in this study. In addition, we also found occlusion of the left pulmonary artery in the pericardium in some cases, usually with a noticeable arterial ligament. Waldman et al[8] believed that this is a spontaneous acquisition of pulmonary artery discontinuity related to the degeneration of the arterial duct tissue. The clinical manifestations and surgical protocols of these patients are the same as those of conventional TOF, so we excluded such patients in this study.

The treatment strategy of TOF combined with UAPA is still very controversial. Surgeons often face the challenge of whether to reconstruct bilateral pulmonary arteries to achieve the ideal " two-lungs repair". At present, there are only sporadic reports on two-lungs correction. Most of the literature is "single-lung repair" or palliative treatment, in which the operative mortality rate was reported to be $44 \%-48 \%$ in the early stage, and recently reduced to $5 \%-8.3 \%[1,3,4,9,10]$. Normal-sized contralateral pulmonary and a well-developed left ventricle are the basis of "single-lung repair" [1]. But due to the inherent pulmonary circulatory dysplasia in TOF patients, even if the unilateral pulmonary artery can meet the criteria of TOF correction and successfully complete the single-lung repair, it is obvious that the damage of the right ventricular function in the procedure and the postoperative pulmonary valve regurgitation will have a huge impact on the long-term prognosis. This is the biggest difference with the isolated UAPA patients.

With the experience in the application of unifocalization technique in the pulmonary atresia with ventricular septal defect, we believe that it is feasible to implement bilateral pulmonary artery reconstruction in TOF with UAPA. It is very important to analyze the computed tomography carefully and to judge the anatomical morphology of the "missing" pulmonary artery with three-dimensional reconstruction. The filling degree and timing of the contrast medium may lead to an underestimation of the development of the pulmonary artery in a CT scan. Cardiovascular MRI may be more helpful for these patients to assess the pulmonary artery. In this 
group of 8 patients, the left hilar confluence is still present, and despite the presence of major aortopulmonary collateral arteries, the inherent left pulmonary artery system covers all lung segments. Neither McGoon nor Nakata Index could meet the criteria of one-stage TOF repair. However, if the left pulmonary artery can be effectively reconstructed, one-stage bilateral pulmonary artery TOF repair could be achieved.

Due to the length of the lacking segment and few available blood vessels tissue, how to reconstruct the connection between the left pulmonary artery and the main pulmonary artery is a challenge for surgeons. Various techniques and reconstructive materials have been reported $[9,10,11,12,13]$. In our institute, different surgeons have chosen different techniques and strategies. During the postoperative follow-up, we found that the proportion of thrombosis after the use of the Goretex vessel was very high and the diameter of the vessel was limited, so it was almost inevitable to replace the vessel again. Although an autologous pericardial patch was used to widen the anterior wall in the direct anastomosis technique, vascular distortion and stenosis of the left pulmonary artery may occur postoperatively because of the greater tension of the anastomosis, and requiring further intervention. We applied a modified technique of extension of the main pulmonary artery sidewall to reconstruct the connection of the left pulmonary artery to the main pulmonary artery, ensuring anastomosis without tension. The short-term results are good, and the long-term results need further follow-up. So far, our institute has not treated patients with TOF combined with the absence of right pulmonary artery, or the absence of left hilar confluence requiring the unifocalization of the collateral arteries.

\section{Study Limitations}

There are some limitations of this study. First, our patients were all admitted for two-lung repair without comparison with one-lung repair. And the number of patients was limited. Additionally, despite the good results of early and mid-term follow-up, the long-time follow-up results are unknown.

\section{Conclusions}

In patients with TOF and UAPA, if there is a pulmonary confluence in the affected hilum, it is feasible to implement bilateral pulmonary artery reconstruction for one-stage TOF correction. The use of pulmonary artery extension technique and autologous tissue to reconstruct the connection between the left pulmonary artery and the main pulmonary artery can reduce the incidence of anastomotic stenosis. The long-term effect needs further follow-up.

\section{Author contributions}

Hujun Cui: Concept/design, Data analysis/interpretation, Drafting article. Yongchao Yang, Hailong Qiu, Jianzheng Cen, Shusheng Wen, Jian Zhuang: Data collection. Jian Zhuang, Jimei Chen: Approval of article.

\section{Acknowledgments}

The authors thank Dr. Jianbin Li, cardiologist, Guangzhou Women and Children's Hospital, Guangzhou, for his illustrations (Figure 2).

\section{Declaration of Conflicting Interests}

The author(s) declared no potential conflicts of interest with respect to the research, authorship, and/or publication of this article.

\section{Funding}

The author(s) received no financial support for the research, authorship, and/or publication of this article.

\section{References}

1. Babu B, Caldarone CA. Management of tetralogy of Fallot with unilateral absence of pulmonary artery: an overview. World J Pediatr Congenit Heart Surg 5(1):70-79

2. Kruzliak P, Syamasundar RP, Novak M, et al. Unilateral absence of pulmonary artery: pathophysiology, symptoms, diagnosis and current treatment. Arch Cardiovasc Dis 2013;106:448-54. 
3. Tengjiao Yang, Jing Sun, Haitao Xu, et al. Surgical Management of Tetralogy of Fallot with Unilateral Absence of the Pulmonary Artery. Pediatric Cardiology (2019) 40:1026-1034

4. Leo A. Bockeria, Vladimir P. Podzolkov, Osman A. Makhachev, et al. Palliative surgical treatment of congenital heart defects associated with unilateral absence of the pulmonary artery. Interactive CardioVascular and Thoracic Surgery 16 (2013) 286-292

5. Ping Wang, Ling Yuan, Juhong Shi, et al. Isolated unilateral absence of pulmonary artery in adulthood: a clinical analysis of 65 cases from a case series and systematic review. J Thorac Dis 2017;9(12):49884996

6. Pfefferkorn JR, Loser H, Pech G, et al. Absent pulmonary artery: a hint to its embryogenesis. Pediatr Cardiol 1982;3:283-6.

7. Jeffrey P. Jacobs, James A. Quintessenza, J. William Gaynor, et al. Congenital Heart Surgery Nomenclature and Database Project: Aortopulmonary Window. Ann Thorac Surg 2000; 69:S44-9

8. J. Deane Waldman, Robert B. Karp, Adriana C. Gittenberger-de Groot, et al. Spontaneous Acquisition of Discontinuous Pulmonary Arteries. Ann Thorac Surg 1996;62: 161-8

9. Kim GB, Ban JE, Bae EJ, et al. Rehabilitation of pulmonary artery in congenital unilateral absence of intrapericardial pulmonary artery. J Thorac Cardiovasc Surg. 2011;141(1): 171-178.

10. Talwar S, Gupta A, Choudhary SK, Airan B. Absent left pulmonary artery and double aortic arch in tetralogy of Fallot: reconstruction using homograft saphenous vein or iliac artery. Interact Cardiovasc Thorac Surg. 2009;8(2): 277-279

11. Kamal K. Pourmoghadam, Matthew C. Schwartz, William M. DeCampli, et al. Novel Approach to Construct Absent Intrapericardial Branch Pulmonary Arteries. Ann Thorac Surg 2015;100:738-40

12. Junichi Koizumi, Tomoyuki Iwase, Shigeto Tsuji, et al. Intrapulmonary artery septation for unilateral absence of the pulmonary artery. Asian Cardiovasc Thorac Ann. 2021 Apr 29. Online ahead of print.

13. Yoshimichi Kosaka, Hiromi Kurosawa, Shuichi Hoshino, et al. Surgery for Unilateral Absence of Pulmonary Artery Using Autologous Tissue. Ann Thorac Surg 2003;76:1281-3

\begin{tabular}{|c|c|c|c|c|c|c|c|c|}
\hline Table & Table & Table & Table & Table & Table & Table & Table & Table \\
\hline 1 & 1 & 1 & 1 & 1 & 1 & 1 & 1 & 1 \\
\hline $\begin{array}{l}\text { Base- } \\
\text { line }\end{array}$ & $\begin{array}{l}\text { Base- } \\
\text { line }\end{array}$ & $\begin{array}{l}\text { Base- } \\
\text { line }\end{array}$ & $\begin{array}{l}\text { Base- } \\
\text { line }\end{array}$ & $\begin{array}{l}\text { Base- } \\
\text { line }\end{array}$ & $\begin{array}{l}\text { Base- } \\
\text { line }\end{array}$ & $\begin{array}{l}\text { Base- } \\
\text { line }\end{array}$ & $\begin{array}{l}\text { Base- } \\
\text { line }\end{array}$ & $\begin{array}{l}\text { Base- } \\
\text { line }\end{array}$ \\
\hline $\begin{array}{l}\mathrm{Pa}- \\
\text { tient }\end{array}$ & $\begin{array}{l}\mathrm{Pa}- \\
\text { tient }\end{array}$ & $\begin{array}{l}\mathrm{Pa}- \\
\text { tient }\end{array}$ & $\begin{array}{l}\mathrm{Pa}- \\
\text { tient }\end{array}$ & $\begin{array}{l}\mathrm{Pa}- \\
\text { tient }\end{array}$ & $\begin{array}{l}\mathrm{Pa}- \\
\text { tient }\end{array}$ & $\begin{array}{l}\mathrm{Pa}- \\
\text { tient }\end{array}$ & $\begin{array}{l}\mathrm{Pa}- \\
\text { tient }\end{array}$ & $\begin{array}{l}\mathrm{Pa}- \\
\text { tient }\end{array}$ \\
\hline $\begin{array}{l}\text { Pro- } \\
\text { file }\end{array}$ & $\begin{array}{l}\text { Pro- } \\
\text { file }\end{array}$ & $\begin{array}{l}\text { Pro- } \\
\text { file } \\
\text { Case1 }\end{array}$ & $\begin{array}{l}\text { Pro- } \\
\text { file } \\
\text { Case } 2\end{array}$ & $\begin{array}{l}\text { Pro- } \\
\text { file } \\
\text { Case } 3\end{array}$ & $\begin{array}{l}\text { Pro- } \\
\text { file } \\
\text { Case } 4\end{array}$ & $\begin{array}{l}\text { Pro- } \\
\text { file } \\
\text { Case } 5\end{array}$ & $\begin{array}{l}\text { Pro- } \\
\text { file } \\
\text { Case } 6\end{array}$ & $\begin{array}{l}\text { Pro- } \\
\text { file } \\
\text { Case } 7\end{array}$ \\
\hline $\begin{array}{l}\text { Age at } \\
\text { the } \\
\text { initial } \\
\text { surgery }\end{array}$ & $\begin{array}{l}\text { Age at } \\
\text { the } \\
\text { initial } \\
\text { surgery }\end{array}$ & $1 \mathrm{y}$ & $8 \mathrm{~m}$ & $3 \mathrm{~m}$ & $1 \mathrm{y} 5 \mathrm{~m}$ & $1 \mathrm{y} 10 \mathrm{~m}$ & $3 \mathrm{~m}$ & $3 y 8 m$ \\
\hline sex & sex & female & male & Male & Male & female & female & male \\
\hline $\begin{array}{l}\text { Body } \\
\text { surface } \\
\text { area }(\mathrm{m} 2)\end{array}$ & $\begin{array}{l}\text { Body } \\
\text { surface } \\
\text { area }(\mathrm{m} 2)\end{array}$ & 0.41 & 0.34 & 0.32 & 0.33 & 0.54 & 0.3 & 0.48 \\
\hline $\mathrm{SpO} 2$ & $\mathrm{SpO} 2$ & 0.82 & 0.67 & 0.71 & 0.71 & 0.72 & 0.68 & 0.71 \\
\hline $\begin{array}{l}\text { Main } \\
\text { data in } \\
\text { Echocar }\end{array}$ & $\begin{array}{l}\text { M-PA } \\
(\mathrm{mm}) \\
\mathrm{cam}\end{array}$ & 9.8 & 4.5 & 5.8 & 8 & 7 & 2 & 7.3 \\
\hline
\end{tabular}




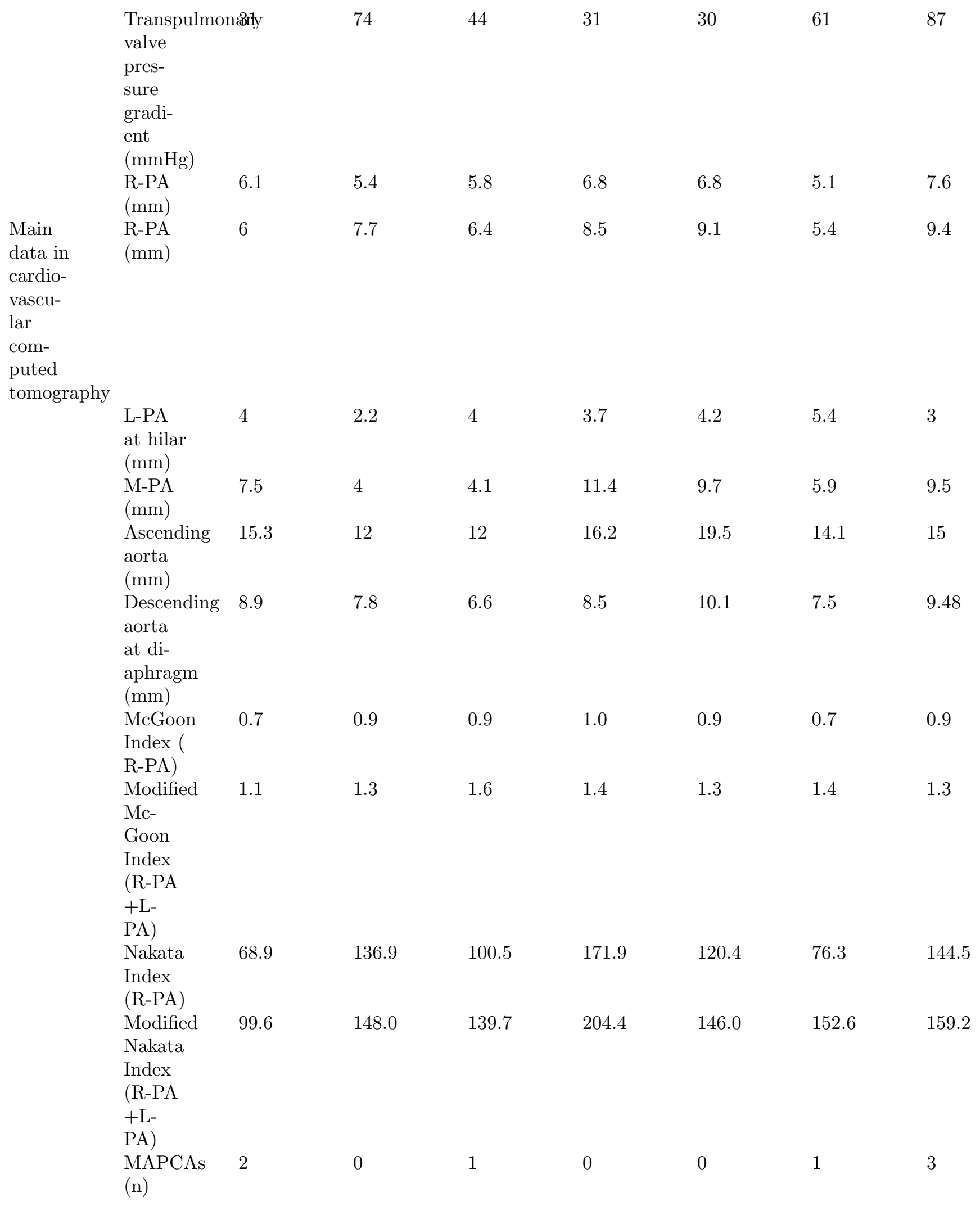




$\begin{array}{llll}\begin{array}{l}\text { Coronary N } \\ \text { Single }\end{array} & \mathrm{N} & \mathrm{N} & \mathrm{N} \\ \text { coro- } & & \text { Single } \\ \text { coro- } & \text { nary } \\ \text { nary } & & \text { artery } \\ \text { artery, } & & \text { LM } \\ \text { RCA } & \text { across } \\ \text { across } & \text { RVOT } \\ \text { RVOT } & \end{array}$




\begin{tabular}{|c|c|c|c|c|c|c|c|c|}
\hline $\begin{array}{l}\text { SpO2: } \\
\text { pluse } \\
\text { blood }\end{array}$ & $\begin{array}{l}\text { SpO2: } \\
\text { pluse } \\
\text { blood }\end{array}$ & $\begin{array}{l}\text { SpO2: } \\
\text { pluse } \\
\text { blood }\end{array}$ & $\begin{array}{l}\text { SpO2: } \\
\text { pluse } \\
\text { blood }\end{array}$ & $\begin{array}{l}\text { SpO2: } \\
\text { pluse } \\
\text { blood }\end{array}$ & $\begin{array}{l}\text { SpO2: } \\
\text { pluse } \\
\text { blood }\end{array}$ & $\begin{array}{l}\text { SpO2: } \\
\text { pluse } \\
\text { blood }\end{array}$ & $\begin{array}{l}\text { SpO2: } \\
\text { pluse } \\
\text { blood }\end{array}$ & $\begin{array}{l}\text { SpO2: } \\
\text { pluse } \\
\text { blood }\end{array}$ \\
\hline oxygen & oxygen & oxygen & oxygen & oxygen & oxygen & oxygen & oxygen & oxygen \\
\hline $\begin{array}{l}\text { satura- } \\
\text { tion; }\end{array}$ & $\begin{array}{l}\text { satura- } \\
\text { tion; }\end{array}$ & $\begin{array}{l}\text { satura- } \\
\text { tion; }\end{array}$ & $\begin{array}{l}\text { satura- } \\
\text { tion; }\end{array}$ & $\begin{array}{l}\text { satura- } \\
\text { tion; }\end{array}$ & $\begin{array}{l}\text { satura- } \\
\text { tion; }\end{array}$ & $\begin{array}{l}\text { satura- } \\
\text { tion; }\end{array}$ & $\begin{array}{l}\text { satura- } \\
\text { tion; }\end{array}$ & $\begin{array}{l}\text { satura- } \\
\text { tion; }\end{array}$ \\
\hline M-PA: & M-PA: & M-PA: & M-PA: & M-PA: & M-PA: & M-PA: & M-PA: & M-PA: \\
\hline main & main & main & main & main & main & main & main & main \\
\hline pul- & pul- & pul- & pul- & pul- & pul- & pul- & pul- & pul- \\
\hline monary & monary & monary & monary & monary & monary & monary & monary & monary \\
\hline artery, & artery, & artery, & artery, & artery, & artery, & artery, & artery, & artery, \\
\hline R-PA: & R-PA: & R-PA: & R-PA: & R-PA: & R-PA: & R-PA: & R-PA: & R-PA: \\
\hline right & right & right & right & right & right & right & right & right \\
\hline pul- & pul- & pul- & pul- & pul- & pul- & pul- & pul- & pul- \\
\hline monary & monary & monary & monary & monary & monary & monary & monary & monary \\
\hline artery, & artery, & artery, & artery, & artery, & artery, & artery, & artery, & artery, \\
\hline L-PA: & L-PA: & L-PA: & L-PA: & L-PA: & L-PA: & L-PA: & L-PA: & L-PA: \\
\hline left & left & left & left & left & left & left & left & left \\
\hline pul- & pul- & pul- & pul- & pul- & pul- & pul- & pul- & pul- \\
\hline monary & monary & monary & monary & monary & monary & monary & monary & monary \\
\hline artery, & artery, & artery, & artery, & artery, & artery, & artery, & artery, & artery, \\
\hline MAP- & MAP- & MAP- & MAP- & MAP- & MAP- & MAP- & MAP- & MAP- \\
\hline CAs: & CAs: & CAs: & CAs: & CAs: & CAs: & CAs: & CAs: & CAs: \\
\hline major & major & major & major & major & major & major & major & major \\
\hline aor- & aor- & aor- & aor- & aor- & aor- & aor- & aor- & aor- \\
\hline topul- & topul- & topul- & topul- & topul- & topul- & topul- & topul- & topul- \\
\hline monary & monary & monary & monary & monary & monary & monary & monary & monary \\
\hline collat- & collat- & collat- & collat- & collat- & collat- & collat- & collat- & collat- \\
\hline eral & eral & eral & eral & eral & eral & eral & eral & eral \\
\hline arter- & arter- & arter- & arter- & arter- & arter- & arter- & arter- & arter- \\
\hline ies, & ies, & ies, & ies, & ies, & ies, & ies, & ies, & ies, \\
\hline RCA: & RCA: & RCA: & RCA: & RCA: & RCA: & RCA: & RCA: & RCA: \\
\hline right & right & right & right & right & right & right & right & right \\
\hline coro- & coro- & coro- & coro- & coro- & coro- & coro- & coro- & coro- \\
\hline nary & nary & nary & nary & nary & nary & nary & nary & nary \\
\hline artery, & artery, & artery, & artery, & artery, & artery, & artery, & artery, & artery, \\
\hline LM: & LM: & LM: & LM: & LM: & LM: & LM: & LM: & LM: \\
\hline left & left & left & left & left & left & left & left & left \\
\hline main & main & main & main & main & main & main & main & main \\
\hline coro- & coro- & coro- & coro- & coro- & coro- & coro- & coro- & coro- \\
\hline nary & nary & nary & nary & nary & nary & nary & nary & nary \\
\hline artery, & artery, & artery, & artery, & artery, & artery, & artery, & artery, & artery, \\
\hline RVOT: & RVOT: & RVOT: & RVOT: & RVOT: & RVOT: & RVOT: & RVOT: & RVOT: \\
\hline right & right & right & right & right & right & right & right & right \\
\hline ven- & ven- & ven- & ven- & ven- & ven- & ven- & ven- & ven- \\
\hline tricular & tricular & tricular & tricular & tricular & tricular & tricular & tricular & tricular \\
\hline outlet & outlet & outlet & outlet & outlet & outlet & outlet & outlet & outlet \\
\hline trace, & trace, & trace, & trace, & trace, & trace, & trace, & trace, & trace, \\
\hline & $\mathrm{N}:$ & & & & $\mathrm{N}:$ & $\mathrm{N}:$ & & \\
\hline normal & normal & normal & normal & normal & normal & normal & normal & normal \\
\hline
\end{tabular}


Table 2 Details of the operations

Operation

Surgical procedure

Ratio of systolic pressure (RV vs AO) after repair L-PA in the recent follow up with echocardiogram L-PA: left pulmonary artry, M-PA: main pulmonary artery, RVOT: right ventricular outlet tract,
Table 2 Details of th

Operation

L-PA reconstrction

M-PA to RVOT

VSD

MAPCAs

Ratio of systolic pressur

$\mathrm{L}-\mathrm{PA}$ in the recent follo

L-PA: left pulmonary ar

\section{Lengeds of the figures}

Figure 1 The 3D print models of the 8 cases. All patients were the left pulmonary artery absence, but the left hilar confluence was present.

Red vessels refer to the aorta and branch arteries; Blue vessels, pulmonary artery; White tube, trachea and bronchi; Yellow vessel, major aortopulmonary collateral arteries; Brown tissue, diaphragm


Figure 2 The modified anastomosis techique

Left, a U-shaped vascular wall was cut from the left side of the main pulmonary artery; Middle, turned over the vessel flap and anastomosed with the posterior wall of the left pulmonary artery, and the anterior wall was widened with an autologous fresh pericardial patch; Right, the reconstructed form.
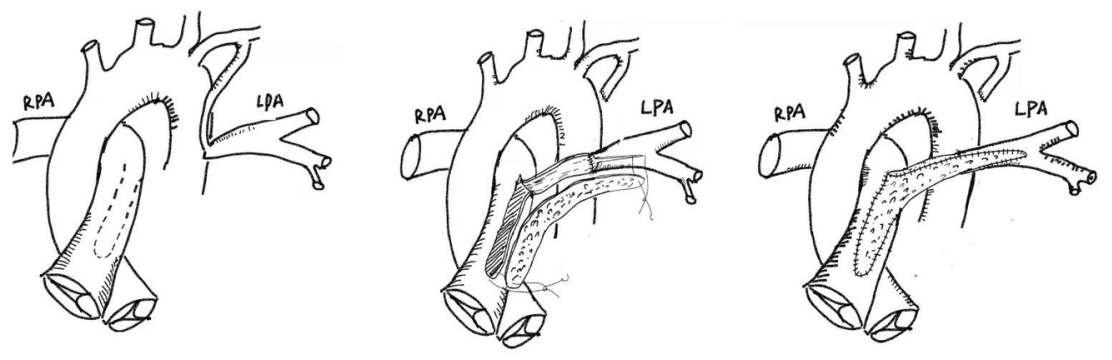
Figure 3 The CT imagings of left pulmonary artery after reconstruction with modified anastomosis technique

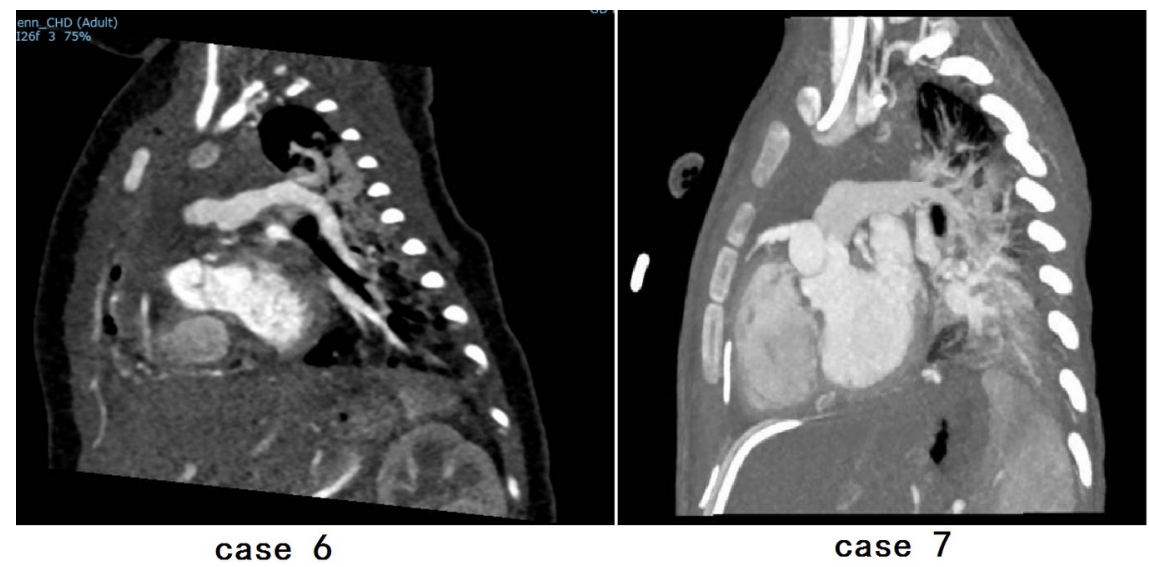

